\title{
Retrospective voting in the Italian 2013 election. A sub-national perspective
}

\author{
MARCO GIULIANI \\ Department of Social and Political Sciences, Università degli studi di Milano \\ marco.giuliani@unimi.it \\ orcid.org/0000-0002-6927-7177
}

\begin{abstract}
The Italian 2013 election ended the period of bipolarism that characterized the so-called "Second Republic", and paved the way for new parties such as the M5S. We investigate that election, which took place after the technocratic government led by Mario Monti, through the analytical lenses of the retrospective theory of voting applied at the provincial level. Local unemployment rates shape the electoral performances of those parties that were more supportive and sympathetic to the caretaker executive, thus confirming a distinction between incumbent and non-incumbent even in that critical and politically undecided election. We further contribute to the literature on retrospective voting by relaxing the locally untenable assumption of independence among the units. Making use of spatial regression models, we demonstrate the relevance of both the internal and contiguous economies, and their relative impact due to the different size of the provinces.
\end{abstract}

\section{Keywords}

Italy, Elections, Voting behavior, Sub-national politics 


\section{Introduction}

In 2013 Italy experienced a veritable political earthquake (Chiaramonte and De Sio, 2014); an electoral tsunami (Chiaramonte, 2014). The two major center-left and center-right party coalitions lost approximately 11 million votes, which went to abstentions and new parties. Among the latter, the Five Stars Movement (M5S) emerged as the biggest party in absolute terms, with more than 25\% of the votes in the lower chamber. The bipolar competition that had characterized the system since the 1994 election gave way to an unprecedented split of votes into three almost equal parts.

The causes of that upheaval are probably manifold, and it falls outside the scope of this paper to explore them. Nonetheless, the Great Recession that was affecting Europe and many other countries in the world certainly played a role in it. This does not automatically mean that the economic situation was directly connected to the defeat of traditional parties, and that the worse the state of the economy, the greater the magnitude of the political earthquake. Yet, it is a hypothesis that it is worth exploring, and it is at the core of our analysis. The very simple idea is to transfer the well-known mechanism of retrospective voting, traditionally applied at the cross-country level, to the subnational one, in order to explore the role played by the state of the economy in the 2013 Italian election.

That transfer is not without problems. To start with, the executive in office at the time of the election, with Mario Monti as prime minister, was a technocratic government. Formally speaking, there were no incumbent parties, although almost the entire parliament initially declared its support for his effort to tackle the economic crisis. Thus, the first research question addressed by this article concerns the possibility of applying the retrospective mechanism even in the presence of an incumbent caretaker government. Are citizens able to distinguish the different parties' contributions to, and support of, a technocratic government that, in a parliamentary system, still needs the confidence of a majority of the legislators? Do they reward and punish them accordingly?

Next, running a within-country investigation requires identification of the appropriate level of analysis. Besides the need to observe at that level both electoral behaviors (our dependent variable) and proxies for the crisis (our independent one), if the units are too many and too small, they cannot provide sufficient leverage for activating the retrospective mechanism. Yet, if they are few in number, and aggregate heterogeneous territories, the risk is that of watering down the effect of the local economy. Thus, our second research question is more methodological, and centers on the adjustments and improvements that must be made to the usual econometric models of the economic vote when they are applied at the sub-national level. What is the appropriate trade-off between homogeneity and number of the units? Can we really consider the economic conditions of sub-portions of the same 
territory as so independent that it is not necessary to model their relationships, or should we try to include the effects of contiguous areas?

We will answer both these research questions by investigating the impact of economic conditions on electoral behavior during the general election that took place on 24-25 February 2013. Anticipating some of the methodological choices that we had to make, as for the absence of formal incumbent parties we sought to identify them by using the positions they took in several salient moments of the legislature, complemented by some data on their public perceptions. We adopted provinces as the territorial unit of analysis because of the possibility of consistently registering their unemployment rates, chosen as proxy for the crisis, and because of their middle position between municipalities and regions. Additionally, we had to relax the assumption regarding the independence of those local units. Indeed, it is unlikely that if the economy influenced electoral behavior, the relationship would remain confined within the borders of each province. Spatial regression models, estimating and discounting the effects of neighbors, help overcome that limit.

The article is organized as follows. In the next section we set the stage by illustrating the economic and political situation in Italy on the eve of the February 2013 election. We then outline the theoretical framework of our study, adapting it to a context in which the incumbent is a caretaker government, and justifying the choice of a sub-national level of investigation. This brings us to formulating our main hypothesis. Subsequently, we operationalize and present our model, describe the dataset that we collected, and illustrate some of the features of our variables at the provincial level. Finally, we report the results of the econometric analyses, and then conclude with some suggestions for future research avenues.

\section{The end of bipolarism}

Mario Monti, head of the caretaker government in office since November 2011, resigned on December 21, 2012. At that time, the Italian economy was at one of the lowest points of the already severe and prolonged recession that hit Europe in 2008. For that year, Eurostat records a negative growth of $-2.8 \%$, much lower than the European average, and a two-digit unemployment rate. According to Istat, the Italian national institute of statistics, almost 900,000 jobs were lost in the 
period from 2008 to $2013 .{ }^{1}$ For half of those years, the domestic product contracted, and, during the election year, for the first time, the GDP per capita fell below the European average. ${ }^{2}$

These objective conditions were mirrored in public perceptions during those months. According to the last wave of Eurobarometer (2012) before the general election, $93 \%$ of Italians judged the economic situation to be "totally bad", 21 percentage points more than the EU-27 average. The three most important issues for the country were all economic. In order of salience, unemployment came first, the overall state of the economy second, and taxation third.

That the Italian economy has been amongst those hardest hit by the Great Recession is well known. Yet it seems an odd twist of fate that it was Monti, a well-known economist and former European commissioner, who suffered politically the most from the economic dynamics that he was supposed to govern. Monti was appointed prime minister by the then president of the Republic, Napolitano, at a time when the spread between Italian and German bonds was close to 600 points. The former executive, led by Silvio Berlusconi, had throughout 2011 been under the strict external supervision of the European institutions, which repeatedly asked for structural reforms. The circulation of a confidential letter signed by Jean-Claude Trichet and Mario Draghi, president of the European Central Bank, which listed the requested policies item by item, provoked a heated political debate. After the summer, all the major international agencies lowered their long- and short-term sovereign credit ratings, and confirmed the negative outlook with another downgrade just a few months afterwards. The financial fire alarms reflected the fragility of the coalition in charge, especially after the split of the People of Freedom party (PdL), and the continuous drain of MPs to the opposition that limited the government's capacity to respond to the ongoing economic crisis effectively (Bosco and McDonnell, 2012).

When Berlusconi eventually resigned, Monti was welcomed as a reassuring signal to Europe and the financial markets. His executive could claim an uncontested level of expertise, being mainly composed of academics with specific competences. ${ }^{3}$ During the confidence debate, Monti presented it as a "government of national responsibility, born to deal with a worrisome emergency, and tackle the economic crisis by restoring the public finance and promoting growth through structural policies" (Italian Senate, sitting n. 637, 17.11.2011). In that contingency, its non-partisan character gained the support of most parliamentary groups, with the sole exception of the Northern League. Eventually, in

\footnotetext{
${ }^{1}$ More specifically, the number of employed people aged over 15 years decreased in that period from 23,090,348 to 22,190,535. http://dati.istat.it/

${ }^{2}$ Eurostat, different indices, http://ec.europa.eu/eurostat/data/database.

${ }^{3}$ The phenomenon of academics involved in politics was not entirely new in Italy (Regonini and Giuliani 1994). But not even the other fully technocratic Italian government, the one led by Lamberto Dini, had the same concentration of university professors.
} 
both chambers, the executive obtained the highest majority ever recorded for an Italian government during the confidence vote.

However, a "full technocratic government" (McDonnel and Valbruzzi, 2014) cannot rely for its political support on any partisan or ideological obligation, so that loyalty risks to be quite volatile. After just one month, some minor parties joined the opposition on the important vote on the annual budgetary policy. The Italy of Values (IdV), the South Tyrolean People's Party (SVP), the People and Territory parliamentary group, and other regional parties like the Valdostan Union (UV) and We the South announced their nay vote or abstention, while several other suspect absences during the vote were registered among center-right and the mixed parliamentary groups. Month after month, Monti's executive had constantly to rely on confidence votes to have its reforms approved (Giannetti, 2013), while there was a growing number of abstentions and opposing votes, especially from rightist parties and MPs, which even managed to have some minor amendments passed (Pedrazzani and Pinto, 2013). Monti's austerity policies, aligned with those of the European Union, soon frustrated the positive public expectations, and they gave rise to growing discontent and public disengagement (Vegetti, Poletti and Segatti, 2014; Giannetti, 2013). At the end of November 2012, the government had once again to table three confidence motions on approval of the budgetary law in the Chamber of Deputies. However, before the law passed to the Senate, the People of Freedom Party (PdL) declared withdrawal of its support from the executive, so that the latter lost its legislative majority. Only after Monti's decision to resign, essentially bringing about anticipated elections, did the PdL permit conclusion of the budgetary process.

The 2013 elections saw several new parties and aggregations competing for the first time. Monti headed a centrist coalition revolving around his newly-founded political list, Civic Choice (SC). Compared to the 2008 election, Bersani extended the center-left coalition both to the left and the center, covering the political space between the Left Ecology Freedom Party (SEL) and the Democratic Center (CD). Berlusconi, on the other side, did more or less the same, with a coalition ranging from the Brothers of Italy Party (FdI) and the Northern League to his People of Freedom Party and other local forces. The array was completed by Grillo's Five Stars Movement (Bordignon and Ceccarini, 2013), Act to Stop the Decline (Fare), a new liberal formation, Civic Revolution (RC), a leftist aggregation with an anti-corruption platform, and several other minor parties which received less than $0.3 \%$ of votes each.

The February 2013 election ended the period of bipolarism of the Italian so-called "Second Republic" (Baldini, 2013; Chiaramonte and Emanuele, 2014). Traditional indices such as the effective number of electoral parties only partially reflect that major transformation, though the peak of 5.3 reached in the 2013 election had never been recorded during the "First Republic", except in 
1992, on the eve of Tangentopoli. Yet the real novelty was that three parties almost evenly split the greatest part of the electorate. While in 2008 the first two parties obtained something more than $70 \%$ of the votes, in 2013 that same percentage was obtained by three parties together, with another 10\% gained by the centrist coalition of the former prime minister (D'Alimonte, Di Virgilio and Maggini, 2013).

\section{The retrospective mechanism}

\section{The local level}

Retrospective voting is recognized as a simple yet powerful mechanism governing the political behavior of citizens in diverse contexts. Voters punish incumbent parties when the economy is performing badly, and reward them when it is booming. Moreover, the magnitude of that punishmentreward mechanism tends to be proportional to the state of the economy, without exhibiting any threshold effect, or saturation. Quantitative analyses take advantage of these characteristics, and they have been able to validate empirically the theory of the economic vote using diverse samples of cases in different periods (Wilkin et al, 1997; Dassonneville and Lewis-Beck, 2014). Some prefer to use surveys and perceptions, because they help in micro-founding the causal mechanism and are directly relevant to explaining the individual behavior. Others prefer to rely on macroeconomic indicators such as growth, unemployment, debt or some aggregate measures of economic performance, since individual perceptions can be highly inaccurate, and standard comparative data can be more easily collected. Yet these methodological debates have mostly helped to refine and improve our understanding, without weakening the overall approach (Lewis-Beck and Stegmaier, 2013).

The retrospective evaluation of the economy as a factor that determines voting choices has been mostly conducted in comparative terms at the national level. That type of research design makes sense both substantively, because of the parallel evaluation of incumbents made by communities of citizens voting in the same country, and statistically because of the independence of those evaluations that respect the assumptions of the econometric models employed. However, there is little to prevent application of the theory also at the sub-national level. Several studies have investigated the link between local performances of incumbents and the state of the national economy (e.g. FauvelleAymar and Lewis-Beck, 2011; Martins and Veiga, 2013). Others have regressed national elections on the local economy (e.g. Johnston et al, 2000; Cutler, 2002). Yet others have sought to keep the local and the national level of both arenas in the same research design (e.g. Johnston and Pattie, 2001; 
Bosch, 2016). This article is rooted in the second tradition. It explores how the local condition of the economy impacts on the local performance of incumbents in a critical national election.

The major methodological advantage of this approach lies in its most similar systems design, which grants higher control compared with the usual cross-country studies. Issues like the different timing, dissimilar institutional setups, diverse political offer and electoral campaign, and many other factors are kept constant using the subnational level to test the incumbent support in a general election. At the same time, this choice does not diminish the variation among the units observed; rather, it recognizes the heterogeneity of situations within the same country. While cross-country analyses require that diversity be smoothed by adopting national averages, a within-case exploration improves our capacity correctly to reflect that varied distribution. Moreover, the local level may represent a good balance between an ego-tropic and a socio-tropic approach to economic voting. Several studies recognize the need for better identification of a reference community (Rogers 2014) which should not necessarily derive from belonging to the same nation-state. The idea of economic localism (Cutler 2002), i.e. the fact that citizens derive their knowledge of the economic situation mostly from their surroundings, is a further justification for taking a subnational perspective. That approach represents a much more demanding test for the theory of economic voting, and, especially on single elections, an optimal setting for assessing its expectations.

\section{A caretaker incumbent}

In the literature on retrospective voting, South-European countries have not been amongst the preferred cases. The comparative lack of analyses has had more to do with local research traditions than with the unattractiveness of the geographical setting. Yet with the Great Recession, beyond the (in)famous PIGS acronym, quantitative and qualitative scholars have started to find clear confirmations of the expected relationship between economic and political arenas in the SouthEuropean countries as well (Bosco and Vernay, 2012; Freire et al., 2014; Karyotis and Rüdig, 2015). Indeed, the particularly severe economic conditions in southern Europe have made the retrospective mechanism even stronger than in other contexts (Lewis-Beck and Nadeu, 2012). Italy is no exception within that area. However, some specifications are necessary. The most important ones have to do with the non-partisan character of the incumbent government, and with the encompassing majority that, at least apparently, supported it.

The second issue is probably less complicated than the first one. Scholars working on incumbents' performance at the party level may disagree on the actual distribution of rewards and punishments within a coalition government, especially due to supposedly blurred responsibilities (Dassonneville and Lewis-Beck, 2014; Debus, Stegmaier and Tosun, 2014; Duch and Stevenson, 
2008). Yet its dimension or oversized status is seldom considered relevant to the overall effect. Even Anderson and Hecht (2012), who analyzed the 2009 German election, recognized that voters personally affected by the initial phases of the recession were unlikely to vote for one of the two parties of the incumbent grand coalition when given the option of voting for some parties in opposition. Even in the absence of any evident alternative coalition, they comparatively preferred to turn to the Liberal-democrats, and even to the Left Party instead of confirming their votes for Cdu and Spd. Furthermore, Plescia (2017) demonstrates in the Italian case that the distribution of incumbents' responsibilities simply follows their different sizes in parliament, without actually considering the distribution of the cabinet portfolios.

However, the technocratic nature of the government, and the ambiguous behavior of some parties, may have muddled their actual support, even suggesting a weak explanatory potential of the retrospective mechanism (Bellucci, 2014). Nevertheless, once we recognize that some parties were patently more loyal than others during the fifteen months before the election, thus being more openly associated with the executive's policies and responsibilities, we can try to extend the usual mechanism of the economic vote also to the 2013 ballot. We will thus distinguish in binary fashion between actual supporters of Monti's government, on the one hand, and both formal opponents and allies in disguise trying to avoid blame for the austerity measures, on the other.

New parties should be considered non-incumbents by definition. This applies, amongst others, to M5S, RC and Fare, but also to parties at the opposite extremes like SEL and FdI. Yet the newly formed Civic Choice is clearly an exception to that rule, since it is led by the former "technocratic" prime minister, and should thus be considered as incumbent, though without any previous electoral experience. The same applies to its allies in the electoral apparentement, the Union of the Centre (UdC), and Future and Freedom (FLI). The Democratic Party (PD), together with its local ramifications, and the Democratic Centre were amongst Monti's most loyal supporters during the $16^{\text {th }}$ legislature, and, in terms of responsibility, they should be considered incumbent as well.

As we saw, only the Northern League cast a contrary vote during the investiture of the executive, but several other parties started to do the same with the first budgetary roll calls. The IdV was the biggest one, together with a few local parties. Yet IdV did not present itself as such during the 2013 campaign, merging with others within the Civic Revolution aggregation. The most difficult case to categorize is the People of Freedom Party. We eventually decided to consider it as nonincumbent for three reasons. Firstly, Monti had to resign because the PdL withdrew its support in both chambers. This reason alone could be sufficient; yet it was complemented by the legislative behaviors of many of the party's MPs during crucial moments of Monti's mandate. Abstentions and absences, together with public statements by the leadership, clearly signaled that the party did not 
want to back the executive consistently. Thirdly, several surveys conducted in the weeks preceding the election showed that, even in the public perception, Monti was closer and more appealing to the electorate of the PD than to that of the PdL. ${ }^{4}$

We believe that our overall classification, which is presented in Table 1, is consistent both with the actors' behaviors during the legislature, and with their profile during the electoral campaign. ${ }^{5}$ Additionally, our reasoning is mirrored in the perceptions that voters had on the different attitudes and strategies of the parties competing in the 2013 election.

*** Tab. 1 approximately here

This leads to the classic retrospective hypothesis, which we will further detail and operationalize in the next section: The worse the state of the economy, the worse the performance of incumbent parties.

\section{Variables, models, data}

In our empirical analysis we check the aforementioned hypothesis using data at the provincial level. The dependent variable is represented by the cumulative share of votes received by incumbent parties, as they have been defined in the preceding section. In Figure 1, we map that distribution, with darker areas representing a higher concentration of votes for the incumbents, and lighter ones the opposite.

\section{*** Fig. 1 approximately here}

The map partially reflects a consolidated distribution in Italy of electoral behaviors or social characteristics (Cartocci, 2007, 2011). Yet, since we do not want to explain that underlying geographical pattern, but rather the impact of the crisis on incumbents support, on the right-hand side

\footnotetext{
${ }^{4}$ E.g. ISPO Ricerche 12.12 .2012 showed that $78 \%$ of the electorate of the PdL thought that Monti should not have stood in the successive election; ISPO Ricerche 11.1.2013 found that only 14\% of voters thought that, after the election, Monti should have formed a coalition with the PdL, while 37\% favored a coalition with the PD. Eventually, Ipsos 7-30.1.2013 found that amongst center-leftist citizens, $49 \%$ liked Monti, while only $22 \%$ of center-rightists did so.

5 Our choice is intrinsically conservative. If PdL had to be considered an incumbent party like the PD, the results of our present models would have been blurred by that erroneous attribution. As a robustness check, we replicated all our analyses, also using a more fine-grained classification that identified an intermediate type of party that formally supported Monti, but actually tried to distinguish itself from his policies. These replications are presented in the online supplementary material, and confirm our results, thus increasing the confidence in our models. Other secondary aspects of the economic vote in that same election, such as the impact of the economy on turnout, volatility, and extra-system volatility can be found in Giuliani and Massari (2018).
} 
of the equation we have to control for the share of votes that those parties received in the preceding 2008 election. At that time, the political offer was not perfectly the same, but in Table 1 we have identified incumbents and non-incumbents in a similar way, irrespective of their electoral aggregation. The IdV, for instance, has been counted as non-incumbent due to its parliamentary behavior during the legislature, in spite of the fact that in 2008 it was on the same electoral ticket as the PD, counted as incumbent in both elections. A further control variable is the change in turnout between the two elections. Citizens' alienation during the Great Recession did not translate exclusively into voice against incumbents; it did so also into exit from the opportunity of be represented by parties (Giuliani and Massari, 2017). Thus, we need to add that confounding variable to our model.

As for the independent variables, before actually testing our hypothesis, we will check the plausibility of the retrospective mechanism using individual data provided by the pre-electoral survey of the Italian national election study (Itanes, 2013). More specifically, we will use the answers to a question on Monti's responsibility for the crisis, which used a scale ranging from 0 - not at all responsible - to 10 - fully responsible, and compute the average of the answers at the provincial level. The cumulative percentage of votes obtained by the incumbents should reflect the distribution of the perceptions regarding responsibility for the poor state of the economy, a direct indicator of the actual work of the retrospective mechanism.

Once checked its plausibility, we more straightforwardly verify our hypothesis by using a direct measure of the real economy. We choose the rate of unemployment, provided by Istat, as a measure of the independent variable for several reasons. Firstly, it is probably the most reliable macroeconomic index available for the provincial level. Next, it is easily perceived by citizens in their neighbourhood, compared to other indices which may be more appropriate for the national level. Thirdly, unemployment has been successfully used both recently (Riera and Russo, 2016) and in previous decades (Bellucci, 1984) to explain electoral behavior in Italy. Lastly, according to the last Eurobarometer before the election, unemployment was the most important issue facing Italy at that time, much more than the generic "economic situation", and it was three percentage points higher than the European average (Eurobarometer, 2012). Since "citizens hold incumbents more responsible for the economic variables that they perceive as being problematic" (Veiga, 2013: 425) we should always try, at least for specific elections, to match our index to their perceptions of saliency. ${ }^{6}$

\footnotetext{
${ }^{6}$ Furthermore, unemployment is the standard index of the real economy used when the economic vote is tested at the subnational level (Johnston et al, 2000; Cutler, 2002; Dassonneville et al, 2016; Riera and Russo, 2016). Provinces represent the lowest administrative level in Italy for which that measure is consistently provided.
} 
Unfortunately, an analysis at the local level cannot realistically rely on the assumption of the independence of the single observations. If some form of contamination or spillover happens even across countries, determining a common mood, shaping shared fears, and producing parallel waves of political behaviors, these effects are much more relevant within the same country, across provinces. First of all, citizens are exposed to the same electoral campaign and political offer. In addition, and what matters most, the economy experiences similar problems in areas and territories regardless to the borders of provinces. If citizens react to the state of the economy, their perceptions are not necessarily limited by the administrative boundaries of their own town. Moreover, due to their work and profession, citizens often commute to a neighboring city, and the assumption that the state of the economy of the nearby province does not affect their behavior is arguable. People living in Rieti, for example, are certainly affected by what happens within their province, but they are definitely not indifferent to what happens in the adjacent Rome. And the same happens for those living in Biella with Turin, or in Cremona with Milan. Generally speaking, there is a problem of mutual spatial dependence of our observations that needs to be taken into account in our models.

Spatial regression models deal exactly with problems of this kind (Neumayer and Plümper, 2016). "More generally, spatial dependence exists whenever [...] one unit of analysis is influenced by the choices [or the state] of other units of analysis" (Neumayer and Plümper, 2010, 2). In our case, we hypothesized that the behavior of citizens in one unit is affected (also) by the state of the economy in other observed units. This particular type of dependence is handled by what are variously called spatial-X, spatial lag of X, or SLX models. Their equation is the following:

$$
y=\alpha+\beta_{1} X+\beta_{2} W X+\varepsilon
$$

where $X$ is a set of explanatory variables, and $W X$ is the spatial lag term for those same variables, with $W$ representing the $n \times n$ connectivity matrix linking each of the $n$ observations to the other ones. The way in which the spatial structure is modeled very much depends on that $W$. The matrix can reflect the contiguity of the different units, assuming a positive value between units sharing a border and zero for those that are not neighbors, or be computed as function of their inverse distance. ${ }^{7}$ We model it by considering lags only for contiguous provinces, which is the easiest and most plausible way to portray their reciprocal influence. ${ }^{8}$ On average, each Italian province has other

\footnotetext{
${ }^{7}$ In the latter case, the influence can decrease more rapidly by taking the inverse of the squared distance (or any other sensible transformation), or be truncated after a certain distance suggested by theory, experience, pragmatic consideration, or rule of thumb.

8 Yet, even considering the inverse of the distances between the capitals of the provinces within a maximum range of approximately 75 kilometers did not produce significant differences in the results.
} 
4.5 neighbors, with a minimum of one in the case of Trieste (with Gorizia), and a maximum of nine in the case of Florence.

*** Tab. 2 approximately here

As we will see, it is worth controlling these effects even for the different sizes of the units, in order not to assume that a tiny province such as Aosta, with its 126,000 inhabitants in 2012, has the same external influence as provinces with more than 3 million residents such as Rome, Naples and Milan. Given its extremely skewed original distribution, we took the logarithm of the population as a measure of those sizes. In Table 2 we summarize the main descriptive features of the variables used in our econometric models. It is evident that there is a high range in the distribution of all our variables. Most of all, the risk of no variation due to the common experience of the Great Recession is avoided. With an average $11 \%$ of unemployment, there are provinces that more than double that number, and others that have less than half of it. Checking empirically if that variation activates different political behaviors is the aim of the analysis reported in the next section.

\section{Empirical results}

We start by checking the plausibility of the retrospective mechanism by using an aggregate measure derived from survey data on the perceived responsibility of Monti for the crisis (see model 1 in Table 3). Given the bounded nature of the dependent variable - the share of votes for incumbents ranges virtually from 0 to 1 - we use a fractional regression, clustering the standard errors at the district level in order to have estimates robust for heteroscedasticity. ${ }^{9}$

Without indulging in an ecological fallacy, provinces in which most blame was placed on Monti's government were the ones that most punished the parties connected with his technocratic executive. The coefficients of this type of model cannot be directly interpreted, but we can compute the marginal effects at specific points of our covariate of interest. For example, after discounting for the past support in 2008 and for the difference in turnout, if the attribution of responsibility to Monti moves from 4 to 5 on its original 10-point scale, the support for incumbents will on average decrease

\footnotetext{
${ }^{9}$ In a few cases, provinces correspond to electoral districts. In others, regions or groups of provinces correspond to districts. By clustering the standard errors, we also controlled for the structure of the competition, and for arbitrary intra-cluster correlations.
} 
from $39.4 \%$ to $37.9 \%$. It is thus clear that the non-partisan character of the executive does not prevent citizens from believing that it should be held politically accountable for its choices.

*** Tab. 3 approximately here

Reassured by this first result, we can proceed by more directly testing our hypothesis concerning the effect of the state of the economy measured by the unemployment rate. Model 2 in Table 3 represents our baseline model, in which we only consider the impact of the economy within the borders of the province, as if there were no spatial spillover from nearby territories. Also in this case, our hypothesis is confirmed. The higher the unemployment, the fewer the votes for incumbent parties.

Model 3 checks the influence on electoral behavior of the economy of contiguous provinces, confirming the same negative effect of unemployment also in the surrounding of each observed unit. Model 4 cumulates and confirms those internal and nearby effects. The higher the rate of unemployment, both within the unit and in the contiguous provinces, the less incumbent parties were successful in the 2013 elections. Yet, since unemployment levels within and around each province are probably associated, they risk competing for the same explanatory effect. Despite the fact that both variables maintain the expected systematic impact on electoral behavior, and notwithstanding a level of collinearity which our tests confirmed to be under control, there are a few signs of stress on the complete model. The level of significance of the coefficients for unemployment, as well as their magnitude, are lower than in the previous models. Thus, the same reasons that suggested including some contagious effect from the surroundings, i.e. the lack of independence among the units, even advices to evaluate separately their contribution, something which is confirmed even by the information criteria reported at the bottom of the models.

There is one last element that we need to introduce to complete our analysis: the differential size and economic importance of the provinces, which we decided to measure through the proxy of the logarithm of the population. The very simple idea is that the bigger a province, the more its internal economy counts. And the bigger the neighbor provinces, i.e. the spatial effects of contiguity, the more the economy of the surroundings will count. In order to check this intuition, we have to interact the internal and contiguous unemployment respectively with the size of the unit, or for its spatial lagged measure. Following the best practices on interaction models (Brambor, Clark and Golder, 2006), we only report the marginal effects of our covariate of interest by plotting them over an appropriate range 
of the interacting variable, along with their confidence intervals (Kam and Franzese, 2007). ${ }^{10}$ This is what we do in Figure 2, which reports the distribution of the cases in the overlaid histograms.

*** Fig. 2 approximately here

The left panel of Figure 2 reports the marginal effect of the within rate of unemployment at different sizes of the province. For almost the entire range of the (log) population, the impact remains negative and systematic, as we could already imagine from the third model of Table 3 . In accordance with our original hypothesis, the negative state of the economy impacts on the electoral behavior, pushing the electorate to punish incumbent parties. All other things being equal, that impact is higher, the bigger the size of the province. The behavior of the electorate in Rome, for instance, is mostly affected by its own unemployment, while that of a medium-sized province, say Modena, is only partially affected by it. Residents of the smaller provinces may even be indifferent to what happens within their borders because their fears, perceptions and reactions are shaped by a wider environment. This is why for the smallest units, i.e. the least populated provinces, the null hypothesis cannot be discarded at the usual level of statistical significance.

The right panel tells the symmetrical story by illustrating the marginal impact of the unemployment rate in the contiguous units at different magnitudes of their (contiguous) population. Comparatively speaking, the bigger the nearby provinces, the more the state of their economy is important, and exactly the opposite for the smaller ones. For a resident in the province of Monza, the fact of living near Milano strongly affects her retrospective voting, while the reverse influence may not be as strong. For approximately $10 \%$ of the provinces that have smaller neighbors, that spatial effect cannot be systematically distinguished from zero. The two graphs together confirm that unemployment limits the electoral possibilities of incumbents, and that the joint effects of the internal and surrounding economies depend on their respective sizes. ${ }^{11}$

\section{Conclusion}

In this article we have tested the retrospective mechanism in the critical 2013 Italian general election at the subnational level. We have added the Italian case to those comparatively few examples in which

\footnotetext{
10 The complete model with the coefficients is included in table A.4 in the online supplementary material.

${ }^{11}$ If we keep the effect of the economy within the provinces constant, and explore the marginal impact of the unemployment of neighbors at their different sizes, we can appreciate that additional external impact in only half of our cases (see fig. A.2 in the supplementary material).
} 
the local state of the economy has been used as a predictor of the results in a national election. This type of approach permits to overcome the limits due to the restricted variance in the answers of survey respondents during severe crises and extra-ordinary times (Lewis-Beck and Costa Lobo, 2017). We have demonstrated that unemployment rates, which were actually very diverse in the 110 Italian provinces in the middle of the Great Recession, are able to explain the variation in electoral behavior in different parts of the country.

We have further contributed to the literature on the economic vote by showing that, in spite of the lack of clarity in the political responsibilities that characterized the 2013 election because of its preceding technocratic government, voters were able to distinguish those parties that entirely backed the policies enacted by the caretaker executive led by Monti from those parties that disapproved them during critical moments of his mandate. It was not only the Northern League that was perceived in opposition; so too were those parties, such as the IdV and PdL, that withdrew their support in different moments of the legislature. In spite of that ambiguity, we have been able to conservatively reconstruct a distinction between incumbents and non-incumbents that has been positively tested in our models. Furthermore, complementing the analysis of the effect of unemployment with that of the subjective perceptions of Monti's faults indirectly substantiates the underlying causal mechanism between the state of the economy and voting behavior.

Our third contribution has been to relax the usual assumption regarding the independence of the information carried by each unit of analysis. Much more than in cross-country studies, it would have been unrealistic to presume that the effects of unemployment and its perceptions do not spill over into contiguous electoral districts. Citizens shape their electoral behaviors using horizons that partially transcend administrative boundaries. If their perspectives were entirely framed nationally, we would have not observed that sub-national variation in the voting behavior. However, if only the local counted, neither would we have registered the impact of contiguous economies, nor would its weight have depended on the size of the different units. We believe that the use of spatial regression models, variably inflected, is an improvement on the instruments used to test the retrospective mechanism not only at the sub-national level but also at the national one. In this increasingly interconnected world, temporal and spatial spillovers and contaminations are becoming much more frequent than in the past, and this type of model helps investigate them and open new avenues for future research in the field. 


\section{Funding}

The research has been funded by the Italian Ministry for Education, University and Research, with the grant 2015P7RCL5, "Politics and Policy in Europe in times of crisis: Causes and consequences"

\section{Data}

The replication data set is available at http://thedata.harvard.edu/dvn/dv/ipsr-risp

\section{Acknowledgments}

I would like to thank the anonymous referees of the journal for their useful comments and suggestions, Marta Mascheroni with whom I initially explored the topic of this article, and Luigi Curini who recommended to check the impact of contiguous economies by using spatial models.

\section{References}

Anderson, C.J. and J.D. Hecht (2012), 'Voting when the economy goes bad, everyone is in charge, and no one is to blame: The case of the 2009 German election', Electoral Studies 31(1): 5-19.

Baldini, G. (2013), 'Don't Count Your Chickens before They're Hatched: The 2013 Italian Parliamentary and Presidential Elections', South European Society and Politics 18(4): 473497.

Bellucci, P. (1984), 'The Effect of Aggregate Economic Conditions on the Political Preferences of the Italian Electorate, 1953-1979', European Journal of Political Research 12(4): 387-401.

Bellucci, P. (2014), 'The Political Consequences of Blame Attribution for the Economic Crisis in the 2013 Italian National Election', Journal Of Elections, Public Opinion And Parties 24(2): 243263.

Bordignon, F. and L. Ceccarini (2013), 'Five Stars and a Cricket. Beppe Grillo Shakes Italian Politics', South European Society and Politics 18(4): 427-449.

Bosch, A. (2016), 'Types of Economic Voting in Regional Elections: The 2012 Catalan Election as a Motivating Case', Journal Of Elections, Public Opinion And Parties 26(1): 115-134

Bosco, A. and S. Verney (2012), 'Electoral Epidemic: The Political Cost of Economic Crisis in Southern Europe, 2010-11', South European Society and Politics 17(2): 129-154. 
Bosco, A. and D. McDonnell (2012), 'Introduction: The Monti Government and the Downgrade of Italian Parties', in A. Bosco and D. McDonnell (eds) From Berlusconi to Monti, New York: Berghahn Books, pp. 37-56.

Brambor, T., W.R. Clark and M. Golder (2006), 'Understanding Interaction Models: Improving Empirical Analyses', Political Analysis 14(1): 63-82.

Cartocci, R. (2007), Mappe del tesoro. Atlante del capitale sociale in Italia, Bologna: il Mulino.

Cartocci, R. (2011), Geografia dell'Italia cattolica, Bologna: il Mulino.

Chiaramonte, A. (2014), The Elections of 2013: A Tsunami with No Winners, in C. Fusaro and A. Kreppel (eds) Still waiting for the transformation, New York: Berghahn Books, pp. 45-63.

Chiaramonte, A. and L. De Sio (eds) (2014), Terremoto Elettorale: Le Elezioni Politiche del 2013, Bologna: Il Mulino.

Chiaramonte, A. and V. Emanuele (2014), 'Bipolarismo addio? Il sistema partitico tra cambiamento e de-istituzionalizzazione', in A. Chiaramonte and L. De Sio (eds) Terremoto Elettorale: Le Elezioni Politiche del 2013, Bologna: Il Mulino, pp. 233-262.

Cutler, F. (2002), 'Local economies, local policy impacts and federal electoral behaviour in Canada', Canadian Journal of Political Science 35(2): 347-382.

D’Alimonte R., A. Di Virgilio and N. Maggini (2013), 'I risultati elettorali: bipolarismo addio?', in Itanes Voto amaro. Disincanto e crisi economica nelle elezioni del 2013, Bologna: il Mulino, pp. 17-32.

Dassonneville, R. and M.S. Lewis-Beck (2014), 'Macroeconomics, economic crisis and electoral outcomes: A national European pool', Acta Politica 49(4): 372-394.

Dassonneville, R., E. Claes and M.S. Lewis-Beck (2016), 'Punishing local incumbents for the local economy: economic voting in the 2012 Belgian municipal elections', Italian Political Science Review 46(1): 3-22.

Debus, M., M. Stegmaier and J. Tosun (2014), 'Economic Voting under Coalition Governments: Evidence from Germany', Political Science Research and Methods 2(1): 49-67.

Duch, R.M. and R.T. Stevenson (2008), The Economic Vote. How Political and Economic Institutions Condition Election Results, Cambridge: Cambridge University Press.

Drukker, D.M., H. Peng, I.R. Prucha and R. Raciborski (2013), 'Creating and managing spatialweighting matrices with the spmat command', The Stata Journal 13(2): 242-286. 
Eurobarometer (2012), Standard Eurobarometer 78, Public opinion in the European Union. First results, Brussels: European Commission.

Fauvelle-Aymar, C. and M.S. Lewis-Beck (2011), 'Second-order elections and economic voting: the French regional example', Rivista Italiana di Scienza Politica 41(3): 369-384.

Freire, A., M. Lisi, I. Andreadis and J.M.L. Viegas (2014), 'Political Representation in Bailed-out Southern Europe: Greece and Portugal Compared', South European Society and Politics 19(4): 413-433.

Giannetti, D. (2013), 'Mario Monti’s Technocratic Government', in A. Di Virgilio and C.M. Radaelli (eds) Technocrats in office, New York: Berghahn Books, pp. 133-152.

Giuliani, M. and S.A. Massari (2017), 'The economic vote at the party level: electoral behaviour during the Great Recession', unpublished paper.

Giuliani, M. and S.A. Massari (2018), It's the Economy, stupid. Votare in tempo di crisi, Bologna: il Mulino, forthcoming.

Itanes (2013), Voto amaro. Disincanto e crisi economica nelle elezioni del 2013, Bologna: il Mulino.

Johnston, R., C. Pattie, D. Dorling, I. MacAllister, H. Tunstall and D. Rossiter (2000), 'Local context, retrospective economic evaluations, and voting: the 1997 general election in England and Wales', Political Behavior 22(2): 121-143.

Johnston, R.J. and C.J. Pattie (2001), “'It's the economy, stupid” - but which economy? Geographical scales, retrospective economic evaluations and voting at the 1997 British general election', Regional Studies 35(4): 309-319.

Kam, C.D. and R.J. Franzese (2007), Modeling and interpreting interactive hypotheses in regression analysis, Ann Arbor: The University of Michigan Press.

Karyotis, G. and W. Rüdig (2015), 'Blame and Punishment? The Electoral Politics of Extreme Austerity in Greece', Political Studies 63(1): 2-24.

Lewis-Beck, M.S. and R. Nadeau (2012), 'PIGS or not? Economic voting in Southern Europe', Electoral Studies 31(3): 472-477.

Lewis-Beck, M.S. and M. Stegmaier (2013), 'The VP-function revisited: a survey of the literature on vote and popularity functions after over 40 years', Public Choice 157(3/4): 367-385.

Lewis-Beck, M.S. and M. Costa Lobo (2017), 'The Economic Vote: Ordinary vs. Extraordinary Times', in K. Arzheimer, J. Evans and M.S. Lewis-Beck (eds) The SAGE Handbook of Electoral Behaviour, London: Sage Publications, vol. 2, pp. 606-629. 
Martins, R. and F.J. Veiga (2013), 'Economic voting in Portuguese municipal elections', Public Choice 155(3): 317-334.

McDonnell, D. and M. Valbruzzi (2014), 'Defining and classifying technocrat-led and technocratic governments', European Journal of Political Research 53(4): 654-671.

Neumayer, E. and T. Plümper (2010), 'Making spatial analysis operational: Commands for generating spatial-effect variables in monadic and dyadic data', The Stata Journal 10(4): 1-21.

Neumayer, E. and T. Plümper (2016), 'W', Political Science Research and Methods 4(1): 175-193.

Passarelli, G. and D. Tuorto (2014), 'Not with my vote: turnout and the economic crisis in Italy', Contemporary Italian Politics 6(2): 427-449.

Pedrazzani, A. and L. Pinto (2013), 'The Work of Parliament in the Year of the Technocratic Government', in A. Di Virgilio and C.M. Radaelli (eds) Technocrats in office, New York: Berghahn Books, pp. 153-172.

Pisati, M. (2014), 'The A to Z of how to create thematic maps of Italy using spmap', Italian Stata Users Group meeting, http://www.stata.com/meeting/italy14/abstracts/materials/it14_pisati.pdf, Milano, November 13-14.

Plescia, C. (2017), 'Portfolio-specific accountability and retrospective voting: the case of Italy', Italian Political Science Review DOI: https://doi.org/10.1017/ipo.2017.11

Regonini, G. and Giuliani, M. (1994), 'Italie: au delà d'une démocratie consensuelle?', in B. Jobert (ed.), Le tournant néo-libéral en Europe: Idées, recettes et pratiques gouvernementales, Paris: Harmattan, pp. 123-199.

Riera, P. and L. Russo (2016), 'Breaking the cartel: the geography of the electoral support of new parties in Italy and Spain', Italian Political Science Review 46(2): 219-241.

Rogers, J. (2014), 'A communotropic theory of economic voting', Electoral Studies, 36: 107-116.

Veiga, L. (2013), 'Voting Functions in the EU-15', Public Choice 157(3): 411-428.

Vegetti, F., M. Poletti and P. Segatti (2014), 'Availability or Disengagement? How Italian citizens reacted to the two-faces parliamentary grand coalition supporting the Monti government?,

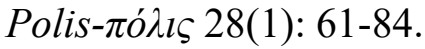

Wilkin, S., B. Haller and H. Norpoth (1997), 'From Argentina to Zambia: a World-Wide Test of Economic Voting', Electoral studies 16(3): 301-316. 
Tab. 1 Parties, their incumbency status, and the number of provinces in which they had candidates

\begin{tabular}{llrlr}
\hline \multicolumn{1}{c}{2013} & prov & prov \\
\hline Incumbents & Autonomie Liberté Démocratie (ALD) & 1 & Autonomie Liberté Démocratie (ALD) & 1 \\
& Civic choice (SC) & 109 & Democratic Party (PD) & 109 \\
& Democratic Centre (CD) & 107 & Socialist Party (PS) & 109 \\
Democratic Party (PD) & 109 & Union of the Centre (UdC) & 109 \\
& Future and Freedom (FLI) & 107 & & \\
& Union of the Centre (UdC) & 110 & & 109 \\
& Union Valdôtaine Progressiste (UVP) & 1 & & 6 \\
& & & 46 \\
Non & Amnesty Justice Freedom (AGL) & 59 & Italy of Values (IdV) & 64 \\
incumbents & 108 & League Autonomy and Pensioners (LA) & 109 \\
& Brothers of Italy (FdI) & 109 & Movement for Autonomy (MpA) & 110 \\
& Civic Revolution (RC) & 110 & Northern League (LN) \\
& Five Star Movement (M5S) & 59 & Südtiroler Volkspartei (SVP) & 1 \\
Great South (GSud) & 109 & The Left - The Rainbow (SA) & \\
Left Ecology Freedom (SEL) & 110 & The People of Freedom (PdL) & \\
Northern League (LN) & 2 & Vallée d'Aoste (VdA) & \\
& Südtiroler Volkspartei (SVP) & 109 & & \\
The People of Freedom (PdL) & 1 & & \\
Vallée d'Aoste (VdA) & & & \\
& & &
\end{tabular}




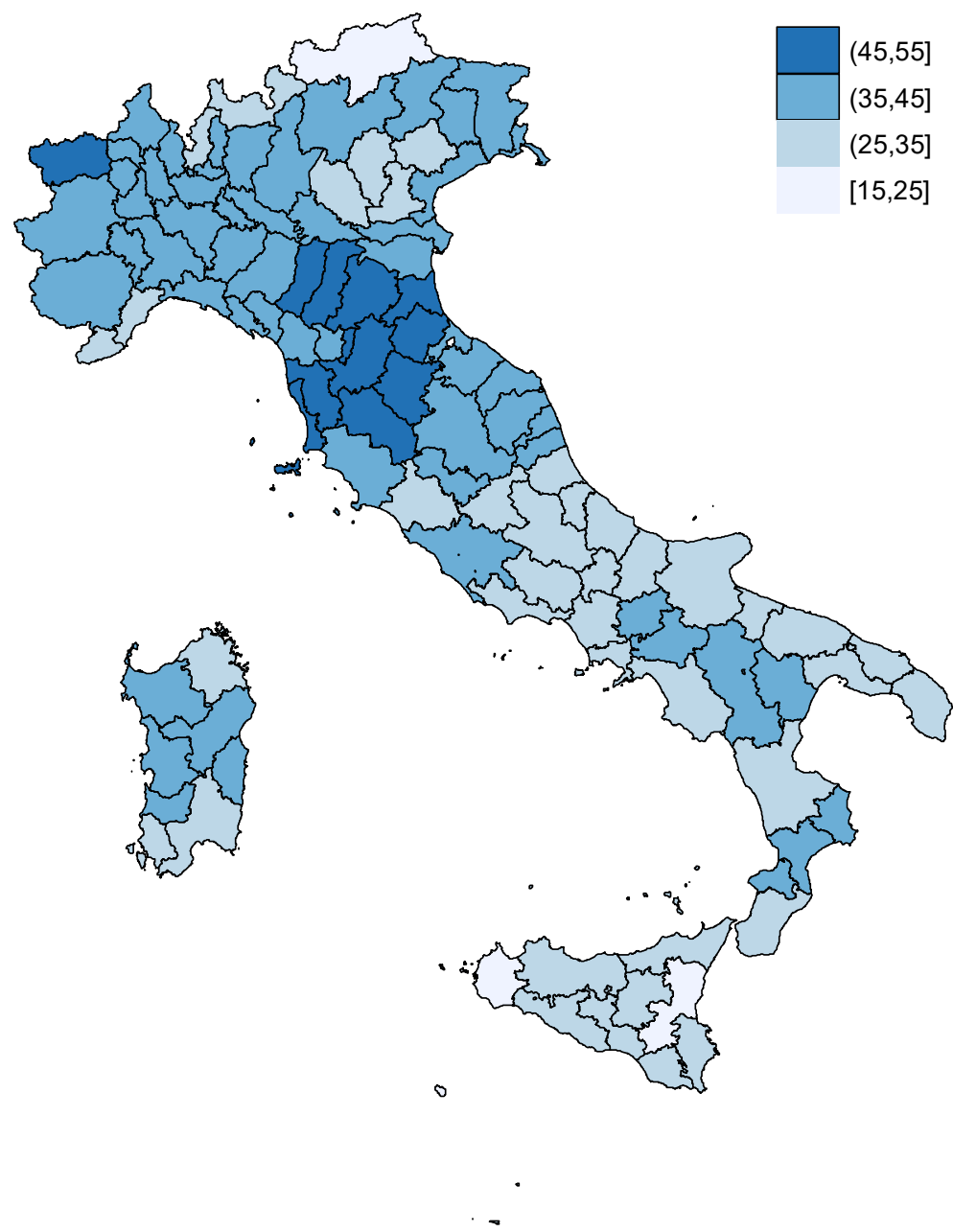

Fig. 1 Percentage of votes for incumbents in 2013 at the provincial level Note: Map created with Istat shapefile data and the spmap package for Stata (Pisati 2014) 
Tab. 2 Descriptive statistics of the main variables

\begin{tabular}{llllll}
\hline & $\mathrm{N}$ & Mean & Std. Dev. & Min & Max \\
\hline Pct incumbents 2008 & 110 & 40.64 & 7.87 & 18.25 & 58.56 \\
Pct incumbents 2013 & 110 & 36.67 & 6.16 & 16.38 & 53.48 \\
Unemployment & 110 & 11.13 & 4.93 & 4.11 & 26.78 \\
Contiguous unemploym. & 110 & 11.03 & 4.36 & 5.72 & 20.20 \\
Difference in turnout & 110 & -5.33 & 2.52 & -14.98 & 0.07 \\
Monti's responsibility & 110 & 5.87 & 0.72 & 3.31 & 8.00 \\
\hline
\end{tabular}


Tab. 3 Determinants of incumbents' vote share in 2013

\begin{tabular}{|c|c|c|c|c|c|c|c|c|}
\hline & \multicolumn{2}{|c|}{ (1) } & \multicolumn{2}{|c|}{ (2) } & \multicolumn{2}{|c|}{ (3) } & \multicolumn{2}{|c|}{ (4) } \\
\hline & coef & se & coef & se & coef & se & coef & se \\
\hline $\begin{array}{l}\text { Share incumbents } \\
2008\end{array}$ & $2.21 * *$ & $(0.44)$ & $2.45 * *$ & $(0.32)$ & $2.42 * *$ & $(0.32)$ & $2.45 * *$ & $(0.32)$ \\
\hline Monti's responsibility & $-0.06 *$ & $(0.03)$ & & & & & & \\
\hline Unemployment & & & $-0.03 * *$ & $(0.00)$ & & & $-0.01+$ & $(0.01)$ \\
\hline Contiguous unempl. & & & & & $-0.03 * *$ & $(0.01)$ & $-0.02 *$ & $(0.01)$ \\
\hline Difference in turnout & 1.58 & $(1.02)$ & 0.69 & $(0.99)$ & -1.07 & $(1.23)$ & -1.19 & (1.16) \\
\hline Constant & $-1.00 * *$ & $(0.22)$ & $-1.30^{* *}$ & $(0.16)$ & $-1.25 * *$ & $(0.16)$ & $-1.26^{* *}$ & $(0.16)$ \\
\hline Observations & 11 & & & & & & 1 & \\
\hline AIC & 0.9 & & & & & & 0.9 & \\
\hline $\mathrm{BIC}$ & $-49^{\prime}$ & & -49 & & & & -49 & \\
\hline
\end{tabular}

Fractional regression coefficients with clustered standard errors in parentheses, $* * \mathrm{p}<0.01, * \mathrm{p}<0.05,+\mathrm{p}<0.1$

Contiguity matrix and spatial lag variables computed using the spmat package for Stata (Drukker et al 2013). 

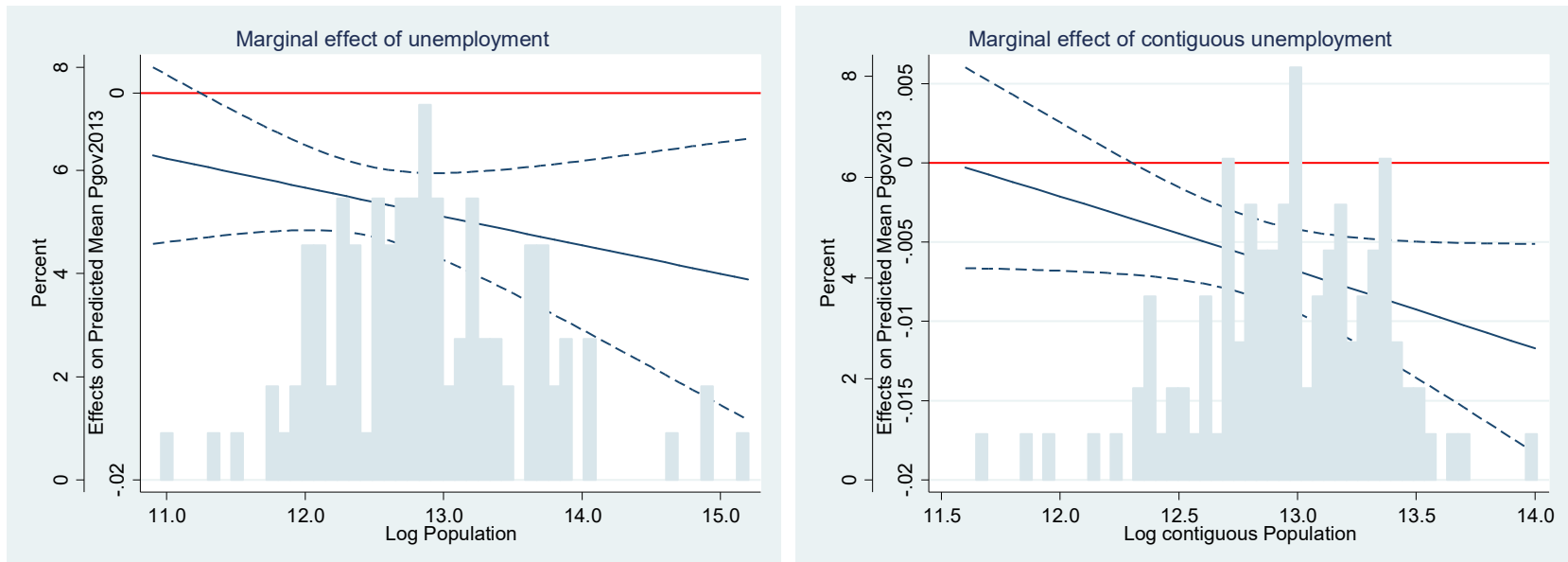

Fig. 2 Marginal effects of unemployment (left panel) and contiguous unemployment (right panel) on the incumbents' votes share for different sizes of the provinces 